\title{
Political Ecology
}

\section{James B. Greenberg and Thomas K. Park}

When business is bad, as the Chinese proverb goes, paint the store. The social sciences unendingly seem to be repainting the store with new fads, yet business remains bad. Some would argue that it is time to tear down the store (I.Wallerstein 1991). Others see this as precisely the problem. We are forever slaying old paradigms. Instead of standing on the shoulders of our predecessors, we take an ax to their knees. As each new approach goes after its precursors with an ax, the social sciences have come to resemble, as Eric Wolf (1990:588) so poignantly phrased it, "a project in intellectual deforestation." The problem, of course, is that while knowledge is socially produced, to launch professional careers, it must be individually appropriated. This fuels the constant demand for the "new and improved," that either adds new bells and whistles to old products or smashes and reassembles them. As old paradigms are cast aside or recycled, so much "new knowledge" has been produced that universities have been forced to continually add new chairs, specialties, and departments. From their common heritage in nineteenth century political and economic philosophy, the social sciences have fragmented into many disciplines.

Political ecology does not amount to a new program for intellectual deforestation, rather it is a historical outgrowth of the central questions asked by the social sciences about the relations between human society, viewed in its bio-cultural-political complexity, and a significantly humanized nature. It develops the common ground where various disciplines intersect. The Journal of Political Ecology welcomes case studies from specialists in agriculture, land tenure, health, development, international law, history, and both the physical and social sciences; major contributions to the study of political ecology have already come from each of these fields. Despite this broad interdisciplinary emphasis, it is possible to delineate two major theoretical thrusts that have most influenced the formation of political ecology. These are political economy, with its insistence on the need to link the distribution of power with productive activity and ecological analysis, with its broader vision of bio-environmental relationships.

The origins of political economy may be found in the works of seventeenth to nineteenth century thinkers such as Hobbes, Adam Smith, Malthus, Ricardo, and Marx. Karl Marx, perhaps, came closest to defining the dialectic between individuals, their productive activity in human society, and nature (I.Mészáros 1970:104) that political ecology seeks to address by his insistence that one must begin not with abstract premises or dogmas (K.Marx and F.Engels 1970 [1846]:42), but with the productive activities of real individuals. This focuses attention on political economy as it transforms and is transformed by individuals and nature. Nature and society are both socially constructed to significant degrees, yet both are determined to some extent by what may be glossed as system-like constraints that are neither the deliberate nor inadvertent products of human purposive activity. Political economy as a field has tended to reduce everything to social constructions, blatantly disregarding all that is not human. This has led to a narrowing of the potential of Marx's more flexible dialectic, and to serious analytical deficiencies. Political ecology expands ecological concepts to respond to this inclusion of cultural and political activity within an analysis of ecosystems that are significantly but not always entirely socially constructed. In this brief introductory note to the Journal of Political Ecology we would like, by way of welcome to future readers and contributors, to briefly 
sketch some of the journal's multifarious intellectual ancestors. In the hope more of simplicity than elegance or completeness we do so under the rubrics Sciences, Social Sciences, and Political Economy before attempting to add some brief summary remarks.

\section{Sciences}

Ecology began as a form of geography with somewhat general and naive discussions of the role of climate, temperature, or altitude on biological systems. German writers, such as Humboldt and Haeckel, were the first to develop these ideas. The latter coined the term oecologie in an 1866 work of the same name in which he defined it broadly as the science of the relations of living organisms to the external world (D.Worster 1985:192). Humboldt travelled widely and through his writings on plant geography (1807) and enthusiasm for nature had a major influence on Charles Darwin (D.Worster 1985:131ff.). A number of the key theoretical ideas current in ecology owe their first formulation to Darwin's The Origin of Species which proposed an evolutionary explanation for the diversity of the world's biological organisms. Darwin argued this diversity was the result of individual competition and the survival of the fittest individuals (with subsequent increased reproductive success). Part of this argument focused on competition at the individual level while another part argued that diversification (via mutation) would open up "places" (viewed almost as a fixed set of niches pre-existing in nature) to organisms and thus eliminate direct competition with unchanged members of the species. The result would eventually be the evolution of new species and the resultant great diversity of species on the planet. Later work in ecology expanded Darwin's ideas in a multitude of ways.

Ecologists have regularly exhibited considerable concern over the scientific character of their research; with evolutionists (generally emphasizing evolution at the individual level) and ecosystem advocates (focusing on the interactions between a community of organisms) each accusing the other camp of insufficient rigor. In each case the arguments have been facilitated by the exclusion of mankind (to say nothing of politics) from the analysis. The proponents of ecosystem analysis take as their starting points Darwin's "entangled bank," the work of Forbes (1887) on the lake as a microcosm, Warming (1895) on plant communities, Cowles' (1899) discussion of plant succession on sand dunes along the shores of Lake Michigan, and Clements' (1905) ideas about plant succession and climax plant communities. These influential works were widely critiqued within the general ecosystem framework. At first, this took the form of eliminating naive and simplistic versions of the theory. This was followed by a major theoretical shift with the development of a new quantitative methodology derived most prominently from Lindeman's 1942 paper, "The Trophic-Dynamic Aspect of Ecology” (J.Hagen 1992:94ff). This paper redirected the focus of ecosystems analysts toward measurement of the flows of energy throughout the various levels of the system; since energy was continually being lost at each level of the ecosystem it appeared more critical than materials which were recycled (although perhaps in simplified forms). This model also had a major influence on the field of cultural ecology prominent in anthropology.

The proponents of an evolutionary perspective tended to insist that ecology must start with Darwin's evolutionary paradigm in which competition at the individual level provides the motive force for change (J.Hagen 1992: 146ff). They argued that what appeared to be communities were no more than assemblages of competing individuals, and that the holistic approach of the ecosystem theorists merely introduced unscientific, unsupportable, and patently ideological elements that diverted attention from more 
significant avenues of research. By 1965, the evolutionary ecology focus on population dynamics and the role of individual selection had begun to replace ecosystem analysis in most academic departments. This reductionism, or replacement of holistic studies by a focus on natural selection and genetic analysis, although satisfying the need of most academic ecologists to be scientific, also meant that ecologists abandoned their role as expert advocates for nature; survival of the fittest could just as easily imply transforming the earth into "factory earth" as preserving the "beauty" of nature. Recent work in biology makes quite explicit the dialectical relationship between organisms and their environment (R.Levins and R.Lewontin 1985).

Although the value of genetic analysis and the evolutionary paradigm are indisputable, the exclusive role of short-term self-interested behavior is at least debatable when only plants or microbes are concerned, and has long been increasingly less persuasive when higher mammals and human societies are concerned. To accept this paradigm for higher mammals, but admit its inadequacy for human society, requires belief that humans alone are different. To reject this paradigm entirely at both higher levels and yet insist on its applicability at lower levels requires an even greater leap of faith. It may well turn out that there is in the biological world a continuum from almost purely self-interested behavior to substantially less than purely self-interested behavior.

The introduction of culture and politics introduces causality at a number of new levels which complement rather than replace the causality associated with evolutionary processes. The members of the Annales school of history, beginning with Braudel (1976[1949]; 1980), have argued persuasively that, at a minimum, short-term events, medium-term conjunctural processes running over decades, and long-term structural processes measured in centuries combine to shape the environment within which individual decisions are made. An adequate analysis of such decisions cannot be usefully reduced to an explanation in terms of short-term self-interested behavior. The relationship between productive activity, human character, and the environment is fluid and both historically and regionally specific. There is a contribution from evolutionary processes but rarely any causal domination.

Recent developments in theory have added a new perspective. There is mounting evidence that the idea of nature achieving a harmonious balance (climax forest or stable ecosystem) may be seriously wrong. Research in non-linear analysis (chaos theory) suggests instead that chaotic disturbances are normal. Historical studies of forests and other ecosystems suggest that species and environmental contexts fluctuate chaotically and that species do not simply reach permanent or even long-term ideal adaptations with their environment (I. Prigogine and I. Stengers 1984; W. Schaeffer 1985; D.Worster 1990). The implications of this new model within the biological sciences are ambiguous. It is not clear that, as a result, the biological success of individual members of a species would depend on enhancing individualistic self-serving behavior or that chaotic fluctuations are themselves the simple result of uncoordinated self-interested behavior. It might be that an exclusive devotion of effort to such behavior would provide an inadequate adaptive response due to the narrow range of variation available to individuals of a species. In contrast, species with the greatest success at producing both varied and adaptable individuals might have an advantage, but this raises the thorny issue of group selection (G. Williams 1966; J. Hagen 1992:151ff.). 


\section{Social Sciences}

Ecological ideas have long had major influences in the fields of health, environmental history, cultural ecology, cybernetic analysis of social and economic systems, human geography, and development theory. In each case ecological ideas have had to be extended in line with social science understandings of the mutual interaction between human society, human productive activity, and the (now only slightly "natural") environment. In the 1960s and 1970s, social scientists under the banner of cultural ecology sought to explore the place of human populations within ecological systems. Using concepts borrowed from ecology (E. Odum 1953), general systems theory (L. Bertalanffy 1969), and cybernetics, they attempted to explain the evolution of specific cultural practices and institutions in terms of adaptations to ecological systems, and to explain how internal dynamics within systems can actually lead to change and development through time (G. Bateson 1972; K. Flannery 1968; B. Nietschmann 1973; R. Rappaport 1967; J. Steward 1955). As this approach became increasingly sophisticated, some investigators sought to quantify energy flows through the ecosystems and the tropic exchanges in which human populations took part. Rappaport's (1967) study of the Tsembaga in the highlands of New Guinea is the epitome of such work. By tracing caloric flows through the ecosystem, Rappaport argued that ritual cycles were used to regulate the growth of pig populations, swidden fallow cycles, and the cyclical patterns of war and peace with neighboring Maring groups. Still, the difficulties of using caloric measures to quantify monetary decisions in complex market economies appeared insurmountable (E. Moran 1990:11-24).

Although micro-approaches had considerable success with small, rural populations, the application of simple ecological models to human societies soon seemed problematic. Some analyses were accused of reifying the ecosystem and over-emphasizing its selfregulatory characteristics and stability. Others were criticized for having no clear criteria for determining the boundaries of systems, and of minimizing the interactions between "defined" local populations and larger wholes in which they are embedded economically and politically. A few studies transcended these limitations by including significant historical research (R. Netting 1981) or by explicitly considering both local political economy and ecological constraints (A.Southall 1976).

The interest in human and cultural origins in anthropology led many anthropologists to studies of modern day hunter-gatherers in the hopes of using today's populations to understand the past. Enthusiasm for knowledge about the past was quickly coupled with enthusiasm for understanding "human nature" as research among hunter-gatherer populations (most notably the San groups of the Kalahari) suggested that hunter-gatherers lived well and peaceably with less than half the daily work hours found among industrial peoples (I.Devore and R.Lee 1968). This research was quickly extrapolated to the bulk of human history and major implications drawn for "human nature" as a product of evolution in comparable circumstances. Criticism of this research quickly developed from the perspective of political economy and centered around historical and current evidence that the populations involved were anything but pristine, had a long history of political and economic involvement with local states, and so could not be used simplistically to represent the bulk of human evolutionary history (R.Elphick and H.Gilomee 1988[1979], C.Schrire 1984; E.Wilmsen 1989).

The key areas of traditional ecology that have influenced ecologists in the social sciences seem to have begun primarily from research looking at interactions between organisms and their environment with resultant insights into structural causality rather 
than beginning from explanations solely in terms of individual self-interested behavior. Explanations of the latter sort have been found in the social sciences at least from the time Hobbes published his Leviathan in 1652, and so there has been no need for the social sciences to borrow them from ecology, for ecology had itself borrowed them from political economy. In the social sciences, however, the role of politics and power have consistently been opposed to explanations posed in an individualistic or adaptationist framework.

Social science research in the health field may be said to start with the assumption that clinical treatment of disease is a cost-inefficient way to maintain health. Public sanitation, for example, eliminates many diseases at a fraction of the cost possible with clinical treatment. From this assumption, the individualistic methodology applied in clinical medicine appears to be a major obstacle, and consequently more holistic or sociological approaches have long seemed an obvious improvement. Cultural systems dealing with health and disease may appear to have greater significance from this perspective than yeoman labor in the trenches of hospital clinics.

With the development of clinical medicine in the 19th century, an emphasis on curing disease began to replace more general societal concerns about health. Concomitantly, prestige and wealth were increasingly associated with clinical medicine, while public health became significantly less remunerative in both senses. By the late 1950's, developments in social and preventive medicine, as well as concerns over environmental factors, had developed into a field of medical ecology that conceived of disease as a "convergence in time and space and within the person of the patient of environmental stimuli" (M.Turshen 1977:48). Because medical ecology focused on disease and individuals, its concept of environment only included biological and socio-cultural factors, and so explained disease within a simplistic framework of stimulus and response.

As a result, medical ecology was unprepared to grapple with more subtle and widespread environmental issues such as those associated with the spread of the capitalist system around the globe that have perhaps as great an impact on the limitations and trajectories the system imposes on health and societal development as in the areas typically studied by clinical medicine. Hughes and Hunter's "Disease and 'development' in tropical Africa" (1970) detailed the need for much more sophisticated uses of ecological concepts in the context of development projects in Africa. The insights of this work grew into a substantially more radical discussion of "the underdevelopment of health" within the field of medical geography which called for research on colonialism, social conditions, nutrition, technology exports, health care and global politics (R.Stock 1986:697). Turshen's 1977 article, "The Political Ecology of Disease" argued early on for a political ecology approach in the health field inspired by insights from political economy. More recently, critiques of biocultural paradigms, medical ecology, and critical medical anthropology seem to be increasingly focused on terminological differences despite major similarities in general conclusions (G.Armelagos, et al. 1992; M.Singer 1989; A.Wiley 1992). It might be more productive to make room for each variant within a common field of discourse such as political ecology.

Similar conclusions have long seemed warranted in the social sciences in general. Cultural ecologists have long insisted on the role of culture in human adaptation and the consequent need to enlarge the unit of analysis to embrace entire culture areas. The logical outcome of this has been incorporation of the broader political and economic systems proposed in the field of political economy. More recently, perspectives have broadened throughout the social sciences to include the role of human activity in transforming and even defining ecosystems (urban ecosystems, agricultural ecosystems, damaged 
ecosystems, etc.). Environmental historians such as Crosby (1986) and Worster (1985, 1993) have begun to provide detailed insights into the past role of human societies in transforming the environment. A politically informed environmental history has also begun to develop (e.g. N.Christenson 1989; E.Jones 1981; L.Ladurie 1972; S.Pyne 1991; R.Rotberg and T.Rabb 1981; I.Simmons 1989 as opposed to J.Malin 1947; F.Turner 1920).

\section{Political Economy}

Coinciding with cultural ecology's rise, dependency theory also emerged in the 1960s and 1970s as a critique aimed squarely at modernization theory, the predominant paradigm guiding economic development policies. Modernization theory, in its attempt to formulate a general model of the emergence of contemporary societies, posited that societies went through a regular series of stages in their economic development (W.Rostow 1960). This paradigm assumed that developing countries were characterized by dual economies-modern capitalist sectors and backward, traditional sectors, and that the latter were survivals from the past that would become increasingly differentiated as they came into contact with the modern world. Dependency theorists (G.Frank 1966, 1967, 1969; F.Cardoso 1972; S.Amin 1976) argued against this dualist position; that quite to the contrary the backward state of these so-called traditional societies is not some original state, but a product of their integration and dependence on the capitalist metropolis. In this view, a hierarchical chain of metropolis-satellite relations linked developed metropolis countries to their dependent satellites; within these, national metropolises were surrounded by regional satellites, which in turn were metropolises for local satellites. At each step in this chain, more powerful elite classes were able to extract surplus from the satellites in their sway. One of the main criticisms leveled at dependency theory was that because in the metropolis-satellite model the role of exchange replaces the role of production (E.Laclau 1971), the model has no internal dynamic through which it can transcend its own contradictions (H.Luton 1976). The over emphasis on the continuity and ubiquity of these hierarchical links between levels dissolves every difference in class content that might lead to change.

World-system theory is a direct outgrowth of the attempts to meet the criticisms of dependency theory (I.Wallerstein 1974). World-system theorists, most notably Immanuel Wallerstein, explicitly characterize their work as an extension of the Annales school of French historical thought of which Fernand Braudel is the leading figure. The most original claims made by world-system theorists have to do with the scope and chronology of the world-system they define. They argue that since the sixteenth century a global market has expanded to include the multiple cultural systems of the world's peoples into a single, integrated economic system characterized by a worldwide division of labor (T.Shannon 1989:20-23). "In this world market, profits are generated by primary producers, whom Wallerstein calls proletarians, no matter how their labor is mobilized. Those profits are appropriated...by capitalists, whom Wallerstein classifies as bourgeois, no matter what the source of their capital" (E.Wolf 1982:22). The growth of this global market and the resulting worldwide division of labor, they argue, has generated structural differences between core, peripheral, and semi-peripheral states or geographic areas. Economically and politically, core states dominate the world-system. Such states are 
characterized by capital-intensive systems of production and use of advanced technologies to produce sophisticated manufactured goods. At the other extreme are peripheral states and colonies, where labor-intensive systems of production predominate. These states primarily supply the world market with raw materials and agricultural commodities. Between these two polar extremes lie the states that constitute the semi-periphery (T.Shannon 1989:24-25).

World-system theory has been subject to many of the same criticisms leveled at dependency theory, to which it is heir. Despite a Marxist terminology, world-system theorists tend to use a simple Weberian (1958:17) definition of capitalism that equates it with stocks of capital and the pursuit of high rates of profit in the market economy. Consequently, once non-capitalist regions have been incorporated within the capitalist division of labor defined by the world market, they are capitalist because the relations of production that define the core define the system (I.Wallerstein 1974:127). Because such emphasis is placed on domination by the core, world-system theory has relatively little to say about social and political processes in the "periphery" other than that their dynamics are geared to meet the requirements of capital accumulation in the "core." These theorists focus much of their analysis on institutions and the technologies of exchange; their analyses tell us more about how surpluses are transferred than they do about the ways they are generated. The monolithic vision of capitalism these models present not only confounds the capitalist mode of production with the capitalist world market, but such dichotomies as "core-periphery" or "metropolis-satellite" serve to efface the heterogeneity among the societies that make up the system. "For Wallerstein, especially, the way social labor is deployed in the production of surpluses is a secondary matter, since for him all surplus producers operating under capitalist relations of exchange are 'proletarians' and all surplus takers "capitalists"” (E.Wolf 1982:297).

Because these macro-approaches to the world-system were more interested in how the core exploited the periphery than in the reactions or ecological adaptations of local populations, not only did these approaches tend to lump the breadth of social and cultural diversity under the rubrics of "periphery" or "traditional society," but they tended to leave unexplored the complex processes by which other modes of production were penetrated, subordinated, transformed, or destroyed as they came into contact with the worldeconomy. With Wolf's (1982) publication of Europe and the People Without History, more social scientists began to explore the complex interactions between local populations and the larger, even global political economies in which they are embedded. In contrast to the world-system theorists, Wolf uses a more traditional Marxist definition of capitalism, and argues that as long as mercantile trade merely skimmed off the surpluses of primary producers, it was not capitalism. Capitalism, in this view, only came into being in the late 18th century when monetary wealth was able to take the "revolutionary road" by monopolizing the means of production, buying labor power and putting it to work. This presentation of the spread of capitalism, not as a monolithic system, but as one of "uneven" development opened the way for exploring its local manifestations and impacts. In the historical process of combining with other modes of production, capitalism introduces new social forms, appropriates or transforms others, and yet -- although subordinate to the capitalist economy; these resulting syncretic modes not only retain some indigenous ingredients, but creatively rework those forms imposed upon them to meet their own needs. 


\section{Political ecology}

There is now, in the social sciences, a developing consensus both that it is not enough to focus on local cultural dynamics or international exchange relations, and that the past and present relationship between policy, politics or political economy in general and the environment needs to be explicitly addressed. This directly introduces concepts of relative power at many levels of environmental and ecological analysis. From chaos theory several new perspectives also have arisen. It may be that linking a multitude of substantively different economies closely together will by itself, for mathematical reasons, produce chaotic swings in prices and production levels (D.Ruelle 1991:80-90) with concomitant repercussions on the environment. On the other hand, an adequate response to a chaotic environment may well require broad social or even international initiatives (T.Park 1992; 1993). From the perspective of political ecology, the environment in question may range from the very largely cultural (e.g. that of the epidemiology of disease in urban settings or even the cultural corpus about health or disease), through the intensely political (e.g. resource endowments for strategic materials) to the fairly significantly natural (e.g. rainforest in remote areas of New Guinea or climate itself).

Political economy has a mixed lineage descending from radical thinkers such as Karl Marx as well as from more conservative precursors of modern economists such as Adam Smith and David Ricardo. Yet, the classical political economists shared an acceptance of the value-laden character of economics and would have considered unacceptable the 20th century separation of politics (in a broad sense) from economics (viewed as a purely scientific enterprise). Different classes had different class interests and hence each was likely to promote policies in its own favor. The non-coincidence of all individual interests, and the potential for collusion, has been at the heart of political economy ever since. Ecology's broad perspectives on our biological and physical environment and its alternative emphases on individual competition and holistic analysis have already shown significant potential for dialogue with the more social and power-centered field of political economy. The debate between proponents of "deep ecology" and those of "eco-socialism" is only the most recent evidence for the flexibility of ecological models (B.Devall 1985; D.Pepper 1993). The space for dialogue between political economy, at its best, and ecology is potentially enormous. As semi-devout Wittgensteinians, we feel it would be illadvised to define "political ecology" and maintain rather that all legitimate forms of political ecology will have some family resemblances but need not share a common core.

\section{Conclusions}

The editors encourage authors to contribute critically and substantively to an increased understanding of the interaction between political and environmental variables broadly conceived. The Journal of Political Ecology is meant to encourage a dialogue centered about research and scholarly case studies and this leaves no room for unscholarly ecopolitics. The journal's on-line forum will, however, accept informed commentary of a more passionate and less fully documented sort as well as notices of a purely informational kind. 


\section{References}

Amin, Samir.

1976. Unequal Development. New York: Monthly Review Press.

Armelagos, George J., Thomas Leatherman, Mary Ryan and Lynn Sibley.

1992. Biocultural Synthesis in Medical Anthropology. Medical Anthropology, 14:35-

52.

Bateson, Gregory.

1972. Steps to an Ecology of Mind. New York: Ballantine.

Bertalanffy, Ludwig Von.

1969. General Systems Theory; Foundations, Development, Applications. New York, G. Braziller.

Braudel, Fernand.

1976[orig.1949]. La Méditerranée et le Monde Méditerranéen à l'Epoque de Philippe II. 3.ed. Paris: A.Colin.

1980. On History. Chicago: The University of Chicago Press. [First published in French 1969].

Cardoso, Fernando Henrique.

1972. Dependency and Development in Latin America. New Left Review 74:83-95.

Christenson, Norman.

1989. Landscape History and Ecological Change. Journal of Forest History 33:116-

25.

Clements, Frederic E.

1905. Research Methods in Ecology. Lincoln, Nebraska.

Cowles, Henry Chandler.

1899. The Ecological Relations of the Vegetation on the Sand dunes of Lake Michigan. Botanical Gazette 27:95-117, 167-202, 281-308, 361-391.

Crosby, Alfred W.

1986. Ecological Imperialism: The Biological Expansion of Europe, 900-1900.

Studies in Environment and History. Cambridge [UK]; New York: Cambridge University Press.

Devall, Bill and George Sessions.

1985. Deep Ecology: Living as if Nature Mattered. Salt Lake City, Utah: G.M. Smith.

Devore, Irwin and R.B.Lee, editors.

1968. Man the Hunter. Chicago: Aldine-Atherton, Inc.

Elphick, Richard and Hermann Giliomee, eds.

1988[1979]. The Shaping of South African Society, 1652-1840. Middletown [Connecticut]: Wesleyan University Press.

Flannery, Kent.

1968. Archeology Systems Theory and Early Mesoamerica. In Anthropological Archeology in the Americas. B. Meggars, editor. Washington, D.C. Anthropological Society of Washington.

Forbes, Stephen A.

1925[1877]. The Lake as a Microcosm. Bulletin of the Illinois Natural History Survey 15:537-550. [Originally published in the Bulletin of the Peoria Scientific Association, 1887] 
Frank, Andre Gunder.

1966. The Development of Underdevelopment. Monthly Review Press 18(7):17-31.

1967. Capitalism and Underdevelopment in Latin America. New York: Monthly Review Press.

1969. Underdevelopment or Revolution? New York: Monthly Review Press.

Hagen, Joel Bartholemew.

1992. An Entangled Bank: The Origins of Ecosystem Ecology. New Brunswick [N.J.]: Rutgers University Press.

Hughes, C.C. and J.M. Hunter.

1970. Disease and 'development' in tropical Africa. Social Science and Medicine. 3:443-493.

Jones, E.L.

1981. The European Miracle: Environments, Economics, and Geopolitics in the History of Europe and Asia. Cambridge: Cambridge University Press.

LaClau, Ernesto.

1971. Feudalism and Capitalism in Latin America. New Left Review 67:19-38.

Ladurie, Le Roy.

1972. Times of Feast, Times of Famine: A History of Climate Since the Year 1000. Trans. Barbara Bray. London: Allen and Unwin.

Lindeman, Raymond L.

1942. The Trophic-Dynamic Aspect of Ecology. Ecology 23: 399-418.

Luton, Harry.

1976. The Satellite/Metropolis Model: A Critique. Theory and Society 3(4):573-581.

Malin, James.

1947. The Grassland of North America, Prolegomena to its History, Lawrence, Kansas.

Marx, Karl, and Fredrick Engels.

1970. The German Ideology. New York: International. [Original edition 1846].

Mészáros, Isván.

1970. Marx's Theory of Alienation. London: Merlin Press.

Moran, Emilio F.

1990. The Ecosystem Approach in Anthropology: From Concept to Practice. Ann Arbor: University of Michigan.

Netting, Robert McC.

1981. Balancing on an Alp. Ecological Change \& Continuity in a Swiss Mountain Community. Cambridge: Cambridge University Press.

Nietschmann, Bernard.

1973. Between Land and Water. New York: Seminar Press.

Odum, E.

1953. Fundamentals of Ecology. Philadelphia: Saunders.

Park, Thomas K.

1992. Early Trends toward Class Stratification: Chaos, Common Property, and Flood Recession Agriculture. American Anthropologist 94(1): 90-117.

1993. Ecology and Risk Management: Stratified Common Property and Flood Recession Agriculture. In Risk and Tenure in Arid Lands. The Political Ecology of 
Development in the Senegal River Basin. Thomas K. Park editor. Tucson: The University of Arizona Press, pp.293-330.

Pepper, David.

1993. Eco-socialism: From Deep Ecology to Social Justice. Andover: Routledge.

Pyne, Stephen J.

1991. Burning Bush: A Fire History of Australia. New York: Henry Holt.

Prigogine, Ilya. and Isabelle Stengers.

1984. Order out of Chaos: Man's New Dialogue with Nature. New York, N.Y.:

Bantam Books.

Rappaport, Roy A.

1967. Pigs for the Ancestors. New Haven: Yale University Press.

Rostow, Walt W.

1960. The Stages of Economic Growth: A Non-Communist Manifesto. Cambridge: Cambridge University Press.

Rotberg, Robert I. and Theodore K. Rabb, editors.

1981. Climate and History: Studies in Interdisciplinary History. Princeton: Princeton University Press.

Ruelle, David.

1991. Change and Chaos. Princeton: Princeton University Press.

Schaeffer, William M.

1985. Order and Chaos in Ecological Systems. Ecology, 66(Feb.):93-106.

Schrire, Carmel.

1984. Past and Present in Hunter-Gatherer Studies. New York: Academic Press.

Shannon, Thomas Richard.

1989. An Introduction to the World System Perspective. Boulder: Westview Press.

Simmons, I.G.

1989. Changing the Face of the Earth: Culture, Environment, History. Oxford: Basil Blackwell.

Singer, Merrill.

1989. The Limitations of Medical Ecology: The concept of Adaptation in the context of Social Stratification and Social Transformation. Medical Anthropology 10:223234.

Southall, Aidan.

1976. Nuer and Dinka are People: Ecology, Ethnicity and Logical Possibility. Man (N.S.) II:463-491.

Steward, Julian.

1955. The Concept and Method of Cultural Ecology. Theory of Culture Change. Urbana: University of Illinois Press.

Stock, Robert.

1986. 'Disease and Development' or 'The Underdevelopment of Health': a Critical Review of Geographical Perspectives on African Health Problems," Social Science and Medicine. 23(7):689-700.

Turner, Frederick Jackson.

1920. The Frontier in American History. New York: H.Holt and Company.

Turshen, Meredeth.

1977. The Political Ecology of Disease. The Review of Radical Political Economics, 9 (1):45-60. 
Wallerstein, Immanuel.

1990. Unthinking Social Science: The Limits of Nineteenth Century Paradigms. Cambridge [UK]: Polity Press.

1974. The Modern World System: Capitalist Agriculture and the Origins of the European World Economy in the Sixteenth Century. New York: Academic Press.

Warming, Eugenius.

1909[1895]. Oecology of plants; an Introduction to the Study of Plant-Communities. Oxford: Clarendon Press. [Translated from original Danish of 1895]

Weber, Max.

1958. The Protestant Ethic and the Spirit of Capitalism. New York: Scribner's. [First pub. in German 1904-1905]

Wiley, Andrea S.

1992. Adaptation and the Biocultural Paradigm in Medical Anthropology: A Critical Review. Medical Anthropology Quarterly 6(3):216-236.

Williams, George Christopher.

1966. Adaptation and Natural Selection; a Critique of some Current Evolutionary Thought. Princeton, N. J., Princeton University Press.

Wilmsen, Edwin N.

1989. Land Filled with Flies: A Political Economy of the Kalahari. Chicago: The University of Chicago Press.

Wolf, Eric.

1990. Distinguished Lecture: Facing Power. American Anthropologist. 92(3):586596.

1982. Europe and the People without History. Berkeley: University of California Press.

Worster, Donald.

1985. Nature's Economy: a History of Ecological Ideas. Studies in Environment and History. [New ed.] Cambridge [UK]; New York: Cambridge University Press.

1990. The Ecology of Order and Chaos. Environmental History Review 14(1-2):1-18.

1993. The Wealth of Nature. Environmental History and the Ecological Imagination. Oxford: Oxford University Press. 